\title{
Optimizing the Use of Oral Anti-Neoplastic Drug Therapy
}

\author{
Maurie Markman \\ Cancer Treatment Centers of America, Eastern Regional Medical Center, Philadelphia, Pa., USA
}

The benefits of oral anti-neoplastic drug therapy appear obvious: improved quality of life resulting from the absence of a requirement for a patient to be treated in a medical facility, possible reduced impact of therapy on the patient's caregiver(s), less cost and resource utilization (compared to systemic delivery), and the realistic potential for more frequent drug administration to optimize efficacy. As a result, an increasing number of oral anticancer drug strategies have been introduced into the clinical arena over the past few years, and this trend is almost certain to continue.

However, there are legitimate concerns associated with oral anti-cancer drug delivery, including the issue of the basic bioavailability of the agents as well as the tremendous heterogeneity associated with absorption within the general population, the impact of toxic effects such as emesis and diarrhea on outcomes, and concerns with ensuring adherence to a prescribed treatment regimen.

The question of compliance is particularly problematic in a setting where low-grade side effects (e.g. nausea, fatigue) may not 'hit the radar' of documented serious events in a clinical trial but may lead to inadequate drug intake outside the rather carefully controlled and supervised research setting and potentially result in reduced therapeutic effectiveness. Thus, an evaluation of the adequacy of adherence to medication delivery for a specific regimen is highly relevant both at the population level and for individual patients. Of note, in those settings where it is hypothesized that efficacy mandates drug concentrations within a relatively narrow range, there will be particular concern to insure adequate adherence to a prescribed program.

In this issue of Oncology, Thivat et al. [1] describe an interesting approach to the monitoring of compliance with oral anti-neoplastic drug therapy. In a small group of patients treated with either capecitabine or aromatase inhibitors, a novel calculation of adherence was examined, which included a sophisticated monitoring system designed to more adequately evaluate the actual timing of drug administration.

Through this novel process, the investigators noted several patients whose drug intake was far less than optimal and for whom educational efforts might lead to a more favorable clinical outcome. The use of this interesting strategy in a larger number of individuals and by other groups will be required before it will be possible to realistically assess the utility of this approach, but the potential for this assessment mechanism to provide a more

\section{KARGER}

Fax +4161306 1234 E-Mail karger@karger.ch www.karger.com
(C) 2012 S. Karger AG, Basel

0030-2414/13/0842-0065\$38.00/0

Accessible online at:

www.karger.com/ocl
Maurie Markman, MD

Cancer Treatment Centers of America

Eastern Regional Medical Center

1331 East Wyoming Avenue, Philadelphia, PA 19124 (USA)

Tel. +1 215537 7502, E-Mail maurie.markman@ctca-hope.com 
reliable evaluation of the adequacy of drug adherence both at the population level and in individual patients for specific anti-cancer regimens is evident.

Finally, it is relevant to acknowledge recent provocative reports suggesting that the timing of oral drug intake (e.g. with or without food) may substantially impact bioavailability and permit a meaningful reduction in the total amount of drug required to achieve optimal concentra- tions of the agent in the systemic compartment [2]. If successfully employed, this approach could have a highly favorable impact on the cost of anti-neoplastic drug therapy. However, implementing such a program will require the ability to carefully control the timing of drug intake. It is possible that the process described by Thivat et al. in this preliminary report (or other such novel approaches to insure drug adherence) may be quite helpful in this area.
References
2 Ratain MJ: Flushing oral oncology drugs down the toilet. J Clin Oncol 2011;29:39583959 . Mahammedi H, Dillies AF, Chollet P, Chevrier R: Adherence with oral oncologic treatment in cancer patients: interest of an adherence score of all dosing errors. Oncology 2013;84:67-74. 